CLINICAL LECTURES OF M. LUGOL ON SCROFULOUS DISEASES.

DELIVERED AT THE HOSPITAL OF SAINT IOUIS. RFPORTED BY M. BARTHEZ. LECTURE III.

TRANSLATED BY J. CHICKERING, M.D. BOSTON.

[Communicated for the Buston Medical and Surgical Journni.]

As some inaccuraries have occurred in our previous report, we slatl correct them in a few words of the analysis. M. Lugol will successively treat of five species of scrofula, to which may be referred the great wariety of cases of this disense. These five species are the following :1. Tuberculous Scrofula. 2. Catarrbal Scrofula. 3. Cutaneous Scrofula. 4. Cellular and adipose Srrofula. 5. Osseous Scrofula.

I.- The tuberculous scrofula is the most conmon. It may almost be said that all scrolulous cases are tuberculous in some respucts : the exceptions are very rare. The production of tubercles is always the seal of scrofula. If you have doulsts whether a person has scrofula, these doubis will be removed when you find tuberiles in any part of the body. Further, tulercles may invade almost every tissue of the boily, as the brain, the lungs, the viscera, the membranes, the bloodiessels and the blood itself.

I1.-C'The catarrhal scrofula, of that of the mucous membranes, presents numerous varieties : the mucous system in all its extent may be at once or successively affected; or it may be only in part afferted, as in scrofulous opblubluia, otitis, angina, and lencorrhœa. But all these affections are of the same nature, and support each other. Thus, ophihalmia, angina, and leucorrhoea, not only may exist ingether, but they succeed each other as long as the scrofulous virus remains.

Among the scrofiulous cases of the mucous membrane, must be ranked worms which are generated in consequence of the calatrhal state of the mucous membrane of the digestive tube, similar to ophthalmia ; this remarkahle state is a frequent indication of scrolula, perbaps as frequent as scrofulous opluhaluia, and often exists wilbuut intestinal worms; its diagnosis is important, because it alone indicates the particular mode of treatment.

III.-The cutanenus scrofula shows itself in several forms :

1. Hypertrophy and induration of certain parts, which, when they are seated in the face, give it a peruliar aspect, called by authors the scrofulous face; this is a loose and indefinite expression, for many scrofulous cases are wiblout it. The scrofulous face exists when the disease is seated in the lace.

2. We must rank in the cutaneous species, the growth of lice, which muliply in such numbers on some children, that no care can prevent it. They are not found on strong and healihy children. Put lice on surh a child, and they will not thrive; it is only on poor, sirkly, or scrofulous children, that they are found. This kind of scrofula may even present the development of a worse kind of the disease. M. Lighol has often seen ophohalmia and cervical tubercles succeed the disappearance of vermin fiom the hairy surface of the body, or rather these last take a new form of scrofula.

3. Sometimes the skin of scrofulous patients is dry and chapped, and has the appearance of lichen, or is greasy and moist. 'These two opposite 
effects, when referred to their cause, may be considered as signs of the scrofulous disease.

4. Chilblains. Most of those who have had in infancy, numerous, tedious, and obstinate chilblains, are scrofulous. It is not too much to consider two out of three persons, thus affected, as scrofulous.

5. The skin ulcerates and becomes red sometimes to a considerable extent, which brings on one of the most troublesome and obstinate forms of cutaneous scrofula. We inust not corfound libese ulcers with the fistulas and ulcerations which are the consequences of caries and tubercles; for in these cases, the skin is altered gradually. These two kinds of ulceration are sometimes confluent, but they are generally separate.

6. Esthionenos. This form is the most frequent : it is generally confined to the skin; but it now and then attacks subjacent parts, and particularly the bones in those cases where scrofula is decidedly of a syphilitic origin.

IV.-The cellular and adipose scrofula often consists in an excessive development and growth of these tissues. This cellular hy pertrophy, usually soft and fabby, is generally accompanied with a fine and white skin, constituting that particular beauty which is not a gond omen. The opposite state is also observed; that is, the atrophy of the cellular and adipose tissues. M. Lugol has seen these two opposite extremes in the same family. It is not rare to see two scrofulous sisters, the one presenting an excessive plumpness of which we are speaking, and the other in whom the development of all the cellular tissues is checked, and consequently in whom there is a leanness which is of a scrofulous character.

V. - The scrofula of the bones appears at the most tender age :

1. Tardy and tedious dentition, accompanied with spasms, not unfrequently arises from this unfortunate predisposition; the scrofulous cliild has not strength to push forward the teeth, and this is badly done, or the child sinks under the effort.

2. A second form is a distortion of the bones. Scrofulous persons are often rickety ; may it not be that all scrofulous persons are rickety?

3. Ought we not to include in this species the accidents connected with the lever of the growth, though such fever belongs more to the whole abnormal economy than to the osseous system in particular? This fever is one of the greatest interest; it is a trying epnch, which decides the fate of scrofulous children; the elements of the disease and those of health seem to be struggling against each other, and the struggle, sometimes critical, gives a happy impulse to puberty ; but, oftener, it is obstinate, and then trings on scrofulous maladies, and stops the growth, and the child always remains sickly.

4. Hypertrophy and caries of the bones, which include a great many species, according to the seat, but they all have a common relation to this point, that the history of all scrofulous white swellings is nearly the same as that of the caries of a phalanx.

These different forms of scrofula present characters always the same, whatever be the seat of the disease. But a very remarkable fact is, that one of these forms rarely exists alone; or rather the disease has at once two or more maladies, or they very closely succeed each other. Thus, one scrofulous patient is at one time affect- 
ed with esthiomenos and tubercles; another will have ophthalmia and tuhercles; a third, caries and rutaneous scrofula ; a fourth unites three or four forms of the same disease: these complications are met will much more frequently than the simple forms of scrofula. On the contrary, among oller diseases, we see esthiomenos sucreeding optsthalmia, arid then itsell gives place to caries or tabercles. M. Lugol has slown us numerous cases of all these varieties of scrofula taking place simulianeously or surcessively. What must be our conclusion from this? That all these disenses are of the same nature, and arise from the same cause. There are not many species of scrofulous diseases- hey are only varieties in the seat and form of a disease which is always the same-which always affects the whole individual, a consideration of the greatest importance in therapeutics. After treating of the resemblance of scrofulous diseases, in order to point out their differences, M. Lugol showed us particular cases in which were exhibited all these varieties found in the sane individual.

Such is a sketch of the clinical lectures of M. Lugol on scrofulous diseases. The patients have furnished examples of all the species and most of the rarieties whose nosological names he mentioned. In the lectures which will follow, scrofulous patients will serve still to show the particular history of the species and varieties, of which M. Lugol will treat, after first giving a history of the cases.

We shall next give the ideas of M. Lugol on this subject, and it will be seen to what extent it is true, as we said at the beginning, that he has found the maierials for his clinical lectures in his own experience.

\section{REMARKS ON DR. BELL'S PRIZE ESSAY.}

[Concluded from page 332.]

"THE view of the relations between body and mind, their varied connections with, and reactions upon each other, presents a field of research extended, and promising the richest and most interesting results to the philosophical inquirer, - a field, as yet, lillle explored," says Dr. Bell. 'This is the Doctor's mistake. It lias been fully and faithfully explored in all its length and lreadth. I hope it will not be considered vaunting if I say that I have mainly deroted more than twenty years of my life, most assiduously, to researches of this kind; and I do not believe that there is a nook or coiner of the feld, of which the Doctor speaks, which I bave not accurately surveyed.; and I an confident that no one is qualifeed to give an opinion on the dietetic character of man, till be has carefully and honestly and fully explored this field. The physiological and psycholngical evidence in relation to the natural dietetic character of man, is full and conclusive : but this cannot be accurately apprehended and appreciated by any one who has not made hiniself thoroughly acquainted with all that can be ascertained concerning "the relations between body and mind, 'their varied connections with, and reactions upon earh oiher;" and if I shall be permitted to present to Dr. Bell and others the results of my liabors, in print, as I hope to, ere long, they will find that, instead of "Utopian dreaming" or wasting my time in ex- 